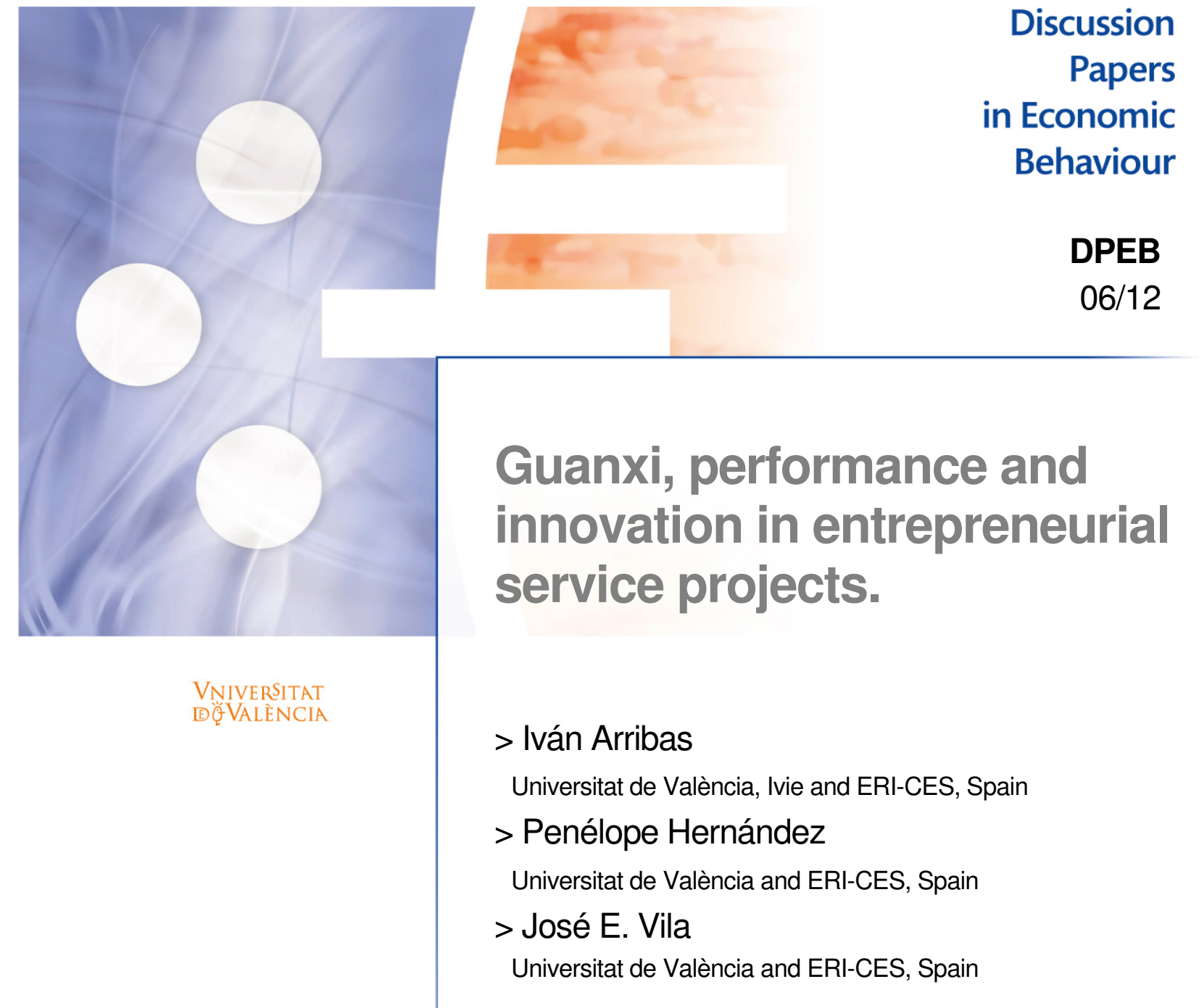

September, 2012 


\title{
Guanxi, performance and innovation in entrepreneurial service projects.
}

\author{
By Iván Arribas ${ }^{(1)}$, Penélope Hernández ${ }^{(2)}$ and José E. Vila ${ }^{(2)}$
}

(1) University of Valencia. Ivie and ERI-CES

${ }^{(2)}$ University of Valencia and ERI-CES. The authors thank both the Spanish Ministry of Science and Technology and the European Feder Funds for financial support under project ECO-2010-20584 and and Generalitat Valenciana (PROMETEO/2009/068).

\begin{abstract}
This paper analyzes the role played by two dimensions of entrepreneurs' private social capital in the survival, growth and innovativeness of entrepreneurial service ventures: local size and preferential attachment degree. We build a bi-dimensional measure of social capital based on network models and a methodology to estimate this measure for any group of entrepreneurs. Based on a survey of service entrepreneurs who launched their business in the city of Shanghai, we show that roles played by each dimension are quite different. A large local size of the network increases the chances of survival of the new venture. However, the chance to become a dynamic venture is only related to entrepreneurs' preferential attachment degree. This finding has relevant political and managerial implications.
\end{abstract}

Keywords: social capital, networks, innovation, entrepreneurship

\section{Introduction}

Academic research on management has shown an increasing interest in analyzing the role played by social capital in SMEs and new ventures as a valuable resource for companies' successful performance as well as an explanatory variable of innovation. The importance of social capital as a determinant of innovation has received much theoretical attention over the last few years. It is now assumed that the acquisition of knowledge by firms does not only depend on the market or the hierarchy, but also on the social capital accumulated within regions through networks of interaction and learning. (Landry et al., 2002). The underlying assumption in this literature on social capital is that economic actors are embedded and nurtured in webs of social relationships and, as social capitalists, they capitalize on resources and assets located in social networks for instrumental actions (Lin 2001).

In this paper, we analyze how entrepreneurs' social capital promotes successful performance and innovation in new ventures within the rapidly changing and fast-paced competitive environment of the Chinese economy. We do know that in economic, political and sociocultural terms, China is different and perhaps even unique. Thus, any research which examines how entrepreneurship is articulated in this particular context can help our understanding. 
Social capital can be analyzed from a macro or micro approach. In a macro analysis, social capital is a public good of a geographic region, social group or a subculture, and it permeates all the economic transactions performed in a social environment. Under a micro approach, social capital is considered a private good, generated by the specific social network of each agent. The amount and consequences of social capital are different for each agent and depend on the structure of their network and their position in it. In this framework, agents are able to manage their networks strategically by creating or destroying links, as well as investing efforts and resources to improve their quality. Entrepreneurs can therefore change the structure of their networks in order to gain competitive advantages or promote innovation. Our paper will consider this last approach.

To develop and estimate empirical models supporting such conclusions, a methodology to measure social capital is required. Establishing such a methodology is a complex matter since advantages provided by social capital will depend on the global structure of the network and the relative position of the agents in it. However, collecting information on the whole network of entrepreneurs involved in any empirical research would be too expensive in terms of time and resources. Therefore, empirical models in the literature are mainly based on the measurement of local properties of entrepreneurs' social network. To cope with this problem, we introduce a bi-dimensional measure of social capital. The first dimension, named local size or degree, is defined as the number of direct links of the entrepreneur with other agents. The second dimension, the preferential attachment degree, is related with the position that such agents occupy in the global structure of the network, specifically their own connection level.

Social connections are important to Chinese people in many aspects of their life, specifically when doing business (Gold et al 2002). Thus, China provides a great opportunity to study the issues related with the impact of social networks and social capital on the performance of new companies. The idea of social capital in the Chinese context captures the indigenous social phenomenon called guanxi (矢系/關係), a word in Mandarin that could be translated into English as connections. Chinese entrepreneurs know the importance of guanxi and become experts in managing their personal networks. Moreover, as China becomes more important in the global economy, many foreign businesses realize that a proper strategy of guanxi management is a key business facilitator in this economy.

\section{Measurement of Social Capital from a network approach}

Let us precisely define the bi-dimensional measure of an economic entrepreneur's social capital. A network is a finite set of nodes (in our case socio-economic agents in Shanghai Society) connected by a series of attachments or links, corresponding to their relationships and interactions. When a new node (i. e. an entrepreneur) is added to the network, they establish new links with existing agents. More formally, we consider that at date $t-1$ there exist a network, say $G_{t-l}$, and at date $t$ a new node, say $i_{t}$, is added. Then, node $i_{t}$ identifies $m$ nodes from $G_{t-1}$, to link with. The inclusion of these new links generates a new network, called $G_{t}$. In 
our case we consider that the entrepreneur establishes a link with a pre-existing agent when they ask this agent for advice or support during the process of launching a new venture.

The addition of the $m$ links node $i_{t}$ establishes at time $t$ plus the links future new-born nodes establishes with node $i_{t}$ defines a first measure of the social capital of $i_{t}$. This measure is named as degree or local size of $i_{t}$. Local size can be considered as a first local measure of the guanxi of an entrepreneur.

Beyond local structure, an entrepreneur can follow different rules to choose which agents to ask for advice or support. There are two extreme situations:

- random attachment: an entrepreneur links with $m$ preexisting nodes that selected uniformly at random. The network structure generate by random attachment is called a random structure.

- preferential attachment: an entrepreneur links with each preexisting node with a probability that is proportional to current number of previous links of such a node. The network structure generated by preferential attachment is called a preferential structure.

We can also consider hybrid models, where the behavior of the entrepreneur varies between these extremes. Then, given a hybrid model, we define the preferential level of the entrepreneur $i_{t}$, denoted by $r$, as the ratio between the new links that are uniformly and randomly formed and the preferential attachment new links. Notice that $r /(1+r)$ can be interpreted as the fraction of new links selected uniformly randomly by $i_{t}$ and $1 /(1+r)$ as the fraction of new links formed under preferential attachment.
We define the preferential attachment degree as the fraction of agents that entrepreneur $i_{t}$ chose under preferential attachment to ask advice or support at any step of the business creation process, given by $1 /(1+r)$. In 4.3 we present a methodology to estimate the average value of the preferential attachment degree for a group on entrepreneurs, taking their degree distribution function as an input.

\section{Research hypothesis}

Entrepreneurs are autonomous, active and selfdirecting economic agents that should behave strategically when establishing and maintaining links in their social environment in order to invest in social capital efficiently. If we consider guanxi from this point of view, it can regarded as a type of behavior where agents use social connections to obtain resources, securing credit or protection as well as market information that is otherwise unavailable (Xin and Pearce, 1996). Guanxi management is a relevant component of the business strategy of any Chinese entrepreneur (Lee and Anderson 2007). Entrepreneurs are expected to manage their social networks to get advice, information or resources from relevant socio-economic agents, establishing their links not under a random but a preferential pattern, as we propose in our first research hypothesis (H1):

H1. Social networks of entrepreneurs have not a random but a preferential structure.

To date, the research literature on social networks and guanxi demonstrated the direct effects of social capital on outcome variables in Chinese economy for both established companies and entrepreneurs (Lee and Anderson 2007). Difficulties in the political and legal interpretations, combined with difficulties 
of accessing resources (Sebera and Li, 2006), create a need for guanxi as a competitive advantage and a strategy potential for new ventures to survive and grow.

On the other hand, the conception of innovation has evolved rather drastically over the last 40 years. During the 1950s, innovation was considered as a discrete event resulting from knowledge developed by isolated inventors and isolated researchers. Nowadays, innovation is rather considered as the result of a process whose success rests upon the interactions and exchanges of knowledge involving a large diversity of actors in situations of interdependence, in what has been defined as co-innovation and co-creation process (Lee et al., 2010). This evolution in the conception of innovation has generated two consequences: first, innovation is no longer conceived as a discrete event only involving the development of technical solutions, but as a process also involving social interactions; second, innovation is no longer explained by the sole combinations of tangible forms of capital (physical, financial,...), but also by combinations of intangible forms of capital, especially social capital (Landry et Al., 2002). The contribution of social capital to innovation is achieved by reducing transaction costs between firms and between firms and other actors, notably search and information costs, bargaining and decision costs, and policing and enforcement costs (Maskell, 2001).

According to the results surveyed above, we propose the following research hypotheses:

H2a. The local size of an entrepreneur's social network is positively related to the chances of their entrepreneurial venture surviving.
$H 2 b$. The local size of an entrepreneur's social network is positively related to the chances of their entrepreneurial project becoming a dynamic venture.

H3a. Preferential attachment degree is positively related to the chances of their entrepreneurial venture surviving.

H3b. Preferential attachment degree is positively related to the chances of their entrepreneurial project becoming a dynamic venture.

\section{Methods}

\subsection{Sample and data collection}

All the variables in the study are from a survey conducted between March and July 2009. The authors prepared the questionnaire, the unit of investigation being the private entrepreneur in the service sector who started up their business between 2001 and 2002 in the city of Shanghai, including those whose company closed before 2009. We consider only these entrepreneurial ventures that started up with fewer than eight hired workers and with no foreign capital. An English and Chinese version of the final questionnaire was prepared and the entrepreneurs could answer each one of them. Data were collected through face-to-face interviews, with the final sample consisting of 105 entrepreneurs.

\subsection{Variables}

Questionnaire items were standard and highly validated for the literature. This article only considers part of the variables in the survey.

\subsubsection{Performance}

The questionnaire has different variables related with the performance of the service companies 
included in the sample, specifically survival, size (sales and employees), growth, profits, internationalization and innovation. Using some of these variables, entrepreneurs' companies were classified into three groups:

- Non surviving ventures: Entrepreneurial firms that did not survive and closed before 2009

- Self-employment ventures: Entrepreneurial firms that survived and were active in 2009 with fewer than eight hired workers

-Dynamic ventures: Entrepreneurial firms active in 2009, with more than eight hired workers and / or implementing any kind of innovation procedure.

\subsubsection{Degree distribution}

We consider that the entrepreneur establishes a link with an agent when they ask this agent for advice or support in any step of the process of creating a new venture. In the interview, we asked the names of all the people contacted by the entrepreneur for this purpose. Thus, each entrepreneur is associated with a value corresponding to their local size and the number of contacts they have. This measure allows us to estimate the empirical degree distribution for the entire sample as well as for each of the three groups of firms defined above.

\subsubsection{Control variables}

An exhaustive review of the literature was undertaken to identify the factors that affect a new venture's performance. The control factors considered were: size, measured as the number of employees, age of the firm, personal characteristics of the entrepreneur, such as gender, age or education and prior experience as a worker and as a business owner.

\subsection{Estimation of social capital measures}

A key characteristic of any network is its degree distribution, which is defined as the relative frequency of nodes that each possible degree has. Degree distribution for hybrid models between random and preferential attachment can be derived. Specifically, Jackson (2008) establishes that the degree distribution has a cumulative distribution function given by:

$$
F(d)=1-\left(\frac{m+2 r m}{d+2 r m}\right)^{(1+r)}
$$

where $d$ denotes any value of the degree, $m$ is the average number of direct links established by entrepreneurs and $r$ is the average ratio between the new links that are uniformly and randomly formed, and the preferential attachment new links. ${ }^{1}$

The cumulative distribution described in (1) is useful for estimating an average measure of both dimensions of social capital (local size and preferential attachment degree) for a group of entrepreneurs when data on their degree distribution is available. Consider an observed network or its degree distribution. The parameter $m$ can be directly calculated from the degree distribution as half of the average degree, and $r$ can be estimated with a least square regression approach. From (1) we have:

$$
\begin{aligned}
& \log (1-F(d))= \\
& 2(1+r) \log (m+2 r m)-2(1+r) \log (d+2 r m)
\end{aligned}
$$

Fixed $m$, we can estimate $r$ as follows. We start with an initial value of the parameter, say $r_{0}$ and regress $\log (1-F(d))$ on $\log \left(d+2 r_{0} m\right)$ to estimate

\footnotetext{
${ }^{1}$ When $r \rightarrow 0$ the degree distribution becomes the power-law distribution that describes the case of pure preferential attachment, $F(d)=1-$ $(m / d)^{2}$; when $r \rightarrow \infty$, the process approaches to the uniformly random link formation.
} 
$2(1+r)$ and obtain a new value $r_{l}$. We iterate this process until a fixed value of $r$ is estimated. We can interpret $m$ as the average intensity of the linking process of a node in the network. The parameter $r$ gives the ratio between the uniformly random links and the preferential links. In our context, nodes are entrepreneurs and links are relationships between individuals to help entrepreneurs in the starting up process. Thus, $2 m$ is the average number of relationships that an entrepreneur uses to support the entrepreneurial activity (i.e. the average degree of the social network) and $1 /(1+r)$ is the fraction of relationships that were selected by an average entrepreneur in a preferential way because the expected outcome should be more valuable than under a random selection.

\subsection{Strategy to test the research hypotheses}

To test our five research hypotheses, our strategy is the following. Firstly, we partition the sample of entrepreneurs into the three separate groups defined in 4.2. A series of control variables, summarizing the most relevant characteristics of the entrepreneur and the company at the moment of its start-up (excepting those related with social capital) are analyzed for each group. We then confirm the homogeneity of the distribution of these control variables among the three groups. If such homogeneity is not rejected, we can conclude that the differences in the performance of the companies in the sample cannot be induced by those control variables. In the next step of the analysis, we follow the technique described in 4.3 to obtain an estimation of the average bidimensional measure of social capital (local size and preferential attachment degree) in the three groups of entrepreneurs. The comparison among these estimated measures allows us to test the hypothesis.

\section{Analysis and results}

\subsection{Homogeneity of the control variables} among groups of service entrepreneurs

The descriptive statistics in Table 1 show relevant information of each factor for the three groups of entrepreneurs according to their performance: non surviving, self-employment and dynamic business. We have tested if factors differ significantly among groups and the resulting p-values of the tests are shown in the last column.

\section{[TABLE 1 ABOVE HERE]}

The overall figures do not differ significantly among the three groups considered (all p-values in the last column of table 1 are higher than $0.05)$. We can conclude that the factors analyzed have the same distribution in the three groups of entrepreneurs and that the difference in the performance is caused by other factors.

\subsection{Estimation of the average degree and preferential linking level}

The degree distribution for each group of entrepreneurs provides the input information to estimate the average of the bi-dimensional measure of their social capital. Table 2 shows the average degree for the three categories of entrepreneurs according to their performance. Entrepreneurs with non-surviving ventures have the lowest average local size. They asked 2.6 relationships for any kind of advice and support and more than $50 \%$ of them contacted only 2 or 3 agents; Entrepreneurs with surviving ventures maintained, on average, around 6 contacts during the starting up phase: 6.0 contacts in the group of self-employment ventures and 6.4 for the ones in the dynamic group. 


\section{[TABLE 2 ABOVE HERE]}

An estimation of the average preferential degree in the three groups of entrepreneurs (Table 2) shows, in addition to having the lowest average degree, the group of entrepreneurs with nonsurviving business has the lowest preferential attachment degree of $26 \%$ : only one in four contacts are established with hubs of the global network. Hence, in this group both measures of social capital are, on average, extremely poor and entrepreneurship failed after the starting of the activity.

Surviving firms were launched by entrepreneurs who maintained, on average, more than double the number of relationships during the starting up process than those of non-surviving firms. In the two groups of surviving firms local size coincides, but the preferential attachment degree is quite different, as can be seen in table 2 . We estimate that $31 \%$ of entrepreneurs' contacts in the self-employment venture group were preferential. This result contrasts with the $98 \%$ of preferential relationships maintained by dynamic entrepreneurs. Entrepreneurs with a large local size and almost completely preferential attachments launched dynamic ventures.

Average degree and percentage of preferential relationships are the two parameters that characterize the degree probability distributions, assuming that those distribute according to the cumulative function given in (1). Therefore, to test whether these parameters differ among the three categories of performance is equivalent to testing whether there are differences in their degree distribution function. We use a refined version of the Li test ( $\mathrm{Li}, 1999)$ to test whether the degree distribution function of a group of entrepreneurs differs significantly from other group. Therefore, if $f$ and $g$ were the degree distributions corresponding to, let us say, the group of non-surviving business and the group of self employment business, the null would be $H_{0}: f(x)=g(x)$ against the alternative, $\mathrm{H}_{1}: \mathrm{f}(\mathrm{x}) \neq$ $\mathrm{g}(\mathrm{x})$. The $p$-values were obtained using 399 bootstrap repetitions. The results, showed in table 3, are conclusive. For all pairs of groups we reject the null hypothesis of equality of distributions. Thus, we can conclude that the observed differences are significant and they are the result of different formation models in the subjacent networks.

\subsection{Test of the research hypothesis}

\subsubsection{Test of hypothesis H1: structure of the} social network

Hypothesis 1 claims that entrepreneurs ask for advice and support from those agents with greater abilities to help them. In this case, the structure of their social network needs to be very close to that of a preferential linking model or, at least, to the structure of a hybrid linking model with a high preferential attachment degree. Our findings, summarized in table 2 , do not support this hypothesis, since the preferential linking model only appears in the group of dynamic entrepreneurs. Thus, some of them (group of non surviving ventures) connect with few agents at the start up of their business. There is no evidence therefore to support that entrepreneurs generally create social networks with preferential structure.

\subsubsection{Test of hypothesis $H 2 a$ and $H 2 b$ : the role} of the local size

Entrepreneurs of surviving firms distinguish from those who started up a non-surviving one in their average local size: surviving firms were 
managed by entrepreneurs with more than double contacts (around 6 on average) than the other. Thus, the chance of a firm to survive is positively related with the local size of the entrepreneur and we accept hypothesis $\mathrm{H} 2 \mathrm{a}$.

On the other hand, and in contradiction with Hypothesis 2b, local size is quite similar for self-employment and dynamic ventures, as expected if local size were related with dynamic ventures. Then, we should reject $\mathrm{H} 2 \mathrm{~b}$.

\subsubsection{Test of hypothesis $H 3 a$ and $H 3 b$ : the role of preferential attachment}

It should be highlighted that almost all (98\%) the contacts made by entrepreneurs with dynamic businesses are preferential, while among those made in the group of selfemployment businesses only $31 \%$ is preferential. This finding supports $\mathrm{H} 3 \mathrm{~b}$.

However, there is not a large difference between the proportion of preferential attachment links in the group of non-surviving and selfemployment ventures (26\% and $31 \%)$. On the contrary, the local size in the second group is more than double the first one. We have to reject $\mathrm{H} 3 \mathrm{a}$.

We can summarize our finding as follows: local size is relevant to guarantee the survival of a new firm, and high preferential attachment degree is needed for a dynamic business.

\section{Discussion}

This paper shows that social capital or guanxi is relevant for business success. Moreover, we define two different dimensions of social capita and show that each of them plays a very different role. A large local size of the network increases the chances of survival of the new venture. However, to launch dynamic innovative companies, entrepreneurs need to have a large preferential attachment degree.

\subsection{Contributions}

A first methodological contribution of this paper is the application of results of networks theory to develop an estimation technique of global properties of social capital, specifically preferential attachment degree, in terms of the local information of the interviewed entrepreneurs. This methodology allows for the analysis of global properties common in empirical social capital literature.

A second contribution is a stress of the role of social capital on the performance and innovation in Chinese new ventures. We show that, if the global structure of the network is also considered, it is possible to establish a direct relation between the global dimension of social capital and the chances of the entrepreneur's project growing and become an innovative company. This conclusion suggests that the role of social capital in the entrepreneurial process could be underestimated systematically, since most of the literature only considers local measures of social capital. This underestimation seems to have a deeper impact when analyzing the phenomenon of entrepreneurial innovation.

\subsection{Managerial and policy implications}

The conclusions of this article have several managerial and policy implications. First of all, we conclude that any entrepreneurial strategy should include an investment plan to generate a minimum level of social capital or guanxi. Moreover, our research establishes some practical implications to manage this guanxi: since the average percentage of preferential linking in the group of entrepreneurs who 
launched dynamic ventures is $98 \%$, we conclude that these entrepreneurs ask for advice and support only to agents that were already hubs in the socio-economic network of Shanghai. In other words, and as was highlighted for other developing and transition economies (Fornoni et al, 2011), an efficient strategy to generate social capital for dynamic entrepreneurship should focus on the creation of quality social capital.

Finally, our results have some implications on innovation and entrepreneurial policy making. Efficient regional development policies should include tools to facilitate local entrepreneurs to link with well-connected agents of the socioeconomic and knowledge network. The establishment of incubators for new start-ups, local clusters or science parks would facilitate that entrepreneurs could get together and create links and alliance among them and with other agents in key positions of the social network. Properly managed, such a policy would increase entrepreneurs' preferential attachment degree and the chances of their start-ups to grow and develop innovation.

\section{References}

Fornoni, M., Arribas, I. and Vila, J. (2011) Measurement of an individual entrepreneur's social capital: a multidimensional model. International Entrepreneurship and Management Journal, 7, 495-507.

Gold, T., Guthrie, D. \& Wank, D. eds. (2002). Social connections in China: Institutions, culture and the changing nature of guanxi. Cambridge University Press. New York.

Jackson, M. O. (2008). Social and economics networks. Princeton University Press (1 ed.) New Jersey.
Landry, R., Amara, N. \& Lamari, M. (2002). Does socialcapital determine innovation? To what extent?. Technological Forecasting and Social Change, 69 (7), 689-701.

Lee, E. Y. \& Anderson, A. R. (2007). The role of guanxi in Chinese entrepreneurship. Journal of Asia Entrepreneurship and Sustainability, $3(3)$.

Lee, S. M., Olson, D. L. \& Trimi, S. (2010). The impact of Convergence on Organizational Innovation. Organizational Dynamics, 39(3).

Li, Q. (1999). Nonparametric testing the similarity of two unknown density functions: local power and bootstrap analysis. Journal of Nonparametric Statistics, 11(1) 189-213.

Lin, N. (2001). Social capital: a theory of social structure and action. Cambridge University Press, Cambridge.

Maskell, P. (2001). Social capital, innovation and competitiveness. In Social Capital: critical perspectives. Baron, S., Field, J. \& Schuller, T. (Eds.) Oxford University Press. Oxford.

Severa, T. \& Li, W. (2006). The effects of economic transitions on Chinese entrepreneurship. Journa of Asia, Entrepreneurship and Sustainability, 2 (3).

Xin, K. R. \& Pearce, J. L. (1996). Guanxi: connections as substitutes for formal institutional support. Academy of Management Journal, 39(6), 16-41. 
Table 1. Descriptive statistics by performance and p-values for the test of differences among groups.

\begin{tabular}{|c|c|c|c|c|c|}
\hline Factors & $\begin{array}{l}\text { Non-surviving } \\
\text { business }\end{array}$ & $\begin{array}{l}\text { Self employment } \\
\text { business }\end{array}$ & $\begin{array}{l}\text { Dynamic } \\
\text { business }\end{array}$ & All business & p-value \\
\hline Sample size (entrepreneurs) & 18 & 58 & 29 & 105 & \\
\hline Entrepreneur's age (years) & $40.1(9.8)$ & $39.4(10.9)$ & $39.5(9.0)$ & $39.5(10.1)$ & 0.908 \\
\hline Females & $22.2 \%$ & $25.9 \%$ & $13.8 \%$ & $21.9 \%$ & 0.442 \\
\hline Size of the firm (employees) ${ }^{a}$ & - & $4.6(2.4)$ & $23.0(10.8)$ & $15.0(3.6)$ & 0.000 \\
\hline Age of the firm (years) & $5.8(1.6)$ & $4.9(1.9)$ & $5.5(2.1)$ & $5.2(1.9)$ & 0.162 \\
\hline $\begin{array}{l}\text { Technical knowledge about } \\
\text { the activity of the firm }\end{array}$ & $66.7 \%$ & $74.1 \%$ & $69.0 \%$ & $71.4 \%$ & 0.783 \\
\hline Courses on starting up & $44.4 \%$ & $36.2 \%$ & $34.5 \%$ & $37.1 \%$ & 0.773 \\
\hline $\begin{array}{c}\text { Previous experience as a } \\
\text { business owner }\end{array}$ & $44.4 \%$ & $32.8 \%$ & $51.7 \%$ & $40.0 . \%$ & 0.218 \\
\hline Working experience (years) & $3.0(1.7)$ & $3.6(2.8)$ & $4.2(4.6)$ & $3.6(3.2)$ & 0.562 \\
\hline $\begin{array}{l}\text { Previous experience as a } \\
\text { worker in companies within } \\
\text { the same activity }\end{array}$ & $55.6 \%$ & $65.5 \%$ & $72.4 \%$ & $65.7 \%$ & 0.499 \\
\hline
\end{tabular}

${ }^{a}$ There is no data on the number of employees for the closed business.

Table 2. Average degree, percentage of strategic links and odds of preferential relationships by performance.

\begin{tabular}{cccc}
\hline Social capital & $\begin{array}{c}\text { Non-surviving } \\
\text { business }\end{array}$ & $\begin{array}{c}\text { Self employment } \\
\text { business }\end{array}$ & $\begin{array}{c}\text { Dynamic } \\
\text { business }\end{array}$ \\
Average degree & 2.6 & 6.0 & 6.4 \\
\% preferential relationships & $26 \%$ & $31 \%$ & $98 \%$ \\
Odds of strategic relationships & 0.35 & 3.76 & 49.00 \\
\hline
\end{tabular}

Table 3 Differences between the degree distribution functions (Li, 1999).

\begin{tabular}{cccc}
\hline Groups of entrepreneurs & & $\begin{array}{c}\text { Self employment } \\
\text { business }\end{array}$ & $\begin{array}{c}\text { Dynamic } \\
\text { business }\end{array}$ \\
Non-surviving & T-statistic & 17.248 & 7.839 \\
Business & p-value & 0.000 & 0.000 \\
Self employment & T-statistic & - & 16.507 \\
business & p-value & - & 0.000 \\
\hline
\end{tabular}

